\title{
Astrocyte elevated gene-1 promotes the proliferation and invasion of breast cancer cells by activating the Wnt/ $\beta$-catenin signaling pathway
}

\author{
MENGXI LI ${ }^{1}$, YUNA DAI $^{1}, \mathrm{LI} \mathrm{WANG}^{2}$ and LEI LI ${ }^{2}$ \\ Departments of ${ }^{1}$ Breast Surgery and ${ }^{2}$ General Surgery, Affiliated Hospital of \\ Hebei Engineering University, Handan, Hebei 056002, P.R. China
}

Received September 2, 2015; Accepted November 28, 2016

DOI: $10.3892 / \mathrm{ol} .2017 .5695$

\begin{abstract}
Astrocyte elevated gene-1 (AEG1) was identified to be overexpressed in breast cancer, and to be associated with the development of breast cancer. In the present study, AEG1 was identified as highly expressed in the MCF-7, MDA-MB-231 and SK-BR-3 breast cancer cell lines and was detected in the MCF-10A normal breast epithelial cell line. The present study established an AEG1-knockdown MCF-7 cell line to investigate the expression status of certain cancer-associated proteins. Western blotting demonstrated that AEG1 may affect cancer cell proliferation and invasion via activating the $\mathrm{Wnt} / \beta$-catenin signaling pathway, a hypothesis that has been supported by cell function tests. The results of the present study demonstrated that when AEG1 was significantly overexpressed in breast cancer cells it promoted cell proliferation and invasion via activating the $\mathrm{Wnt} / \beta$-catenin signaling pathway. Therefore, AEG1 may serve as a novel therapeutic target in breast cancer.
\end{abstract}

\section{Introduction}

Breast cancer is a common type of malignancy; the incidence of the disease has increased in recent years worldwide, currently ranking first with respect to cancer-associated morbidity in women (1-3). The traditional methods of treatment include surgery, radiotherapy and chemotherapy for patients with advanced breast cancer exhibit poor efficacy (4). Therefore, the development of gene-targeted therapy for breast cancer requires further attention. Previous studies have revealed that numerous genes are involved in the occurrence and development of breast cancer, including cyclin D1,

Correspondence to: Dr Lei Li, Department of General Surgery, Affiliated Hospital of Hebei Engineering University, 81 Congtai Road, Handan, Hebei 056002, P.R. China

E-mail: yanwuliaorao123@sina.com

Key words: breast cancer, Wnt/ $\beta$-catenin signaling pathway, astrocyte elevated gene-1, proliferation, invasion matrix metalloproteinases (MMPs) and E-cadherin (5-8). Astrocyte elevated gene-1 (AEG1) has also been investigated with respect to poor prognosis in breast cancer (9). AEG1 is a potentially crucial mediator of tumor malignancy and a key converging point of a complex network of oncogenic signaling pathways (10-12). Previous studies revealed that the AEG1 gene was significantly overexpressed in a number of types of malignant cells, and is associated with tumorigenesis, proliferation, invasion and metastasis $(13,14)$. Statistics also demonstrated that AEG1 was upregulated in breast cancer tissue and positively correlated with clinical stage and lymph node metastasis (15).

The Wnt signaling pathway is one of the most important intracellular signal transduction pathways, and it affects the activated state of multiple effector molecules downstream (16-19). It is closely associated with a variety of human tumor developments, and serves an important role in breast cancer cell proliferation and invasion $(20,21)$. However, the mechanisms that underlie the activation of the Wnt signaling pathway in various types of breast cancer have yet to be identified. $\beta$-catenin has been revealed as a central regulator in the Wnt signaling pathway, and is associated with disease progression and poor prognosis in breast cancer (22). Typically, during activation of the Wnt signaling pathway, $\beta$-catenin accumulates in the cytosol at high levels, binds to T-cell factor/lymphoid enhancer factors and the resulting complex is shuttled to the nucleus, leading to the activation and expression of target genes, including MMP9, cyclin D1 and c-Myc (23). Thus, a high level of $\beta$-catenin in the nucleus is an indicator of an active Wnt signaling pathway.

In the present study, the knockdown of AEG1 expression in MCF7 breast cancer cells was carried out in order to investigate the effect on, and possible mechanism underlying, breast cancer cell proliferation and invasion. The results of the present study suggest that AEG1 may promote the proliferation and invasion of breast cancer cells by enhancing Wnt/ $\beta$-catenin activation.

\section{Materials and methods}

Cell culture and infection. All breast cancer cell lines (MCF7, MDA-MB-231, SK-BR-3) were obtained from the Cell Bank of 
Chinese Academy of Sciences (Shanghai, China). The MCF7 cells were cultured in Dulbecco's modified Eagle medium (DMEM; HyClone; GE Healthcare Life Sciences, Logan, UT, USA) supplemented with $10 \%$ fetal bovine serum (FBS; Gibco; Thermo Fisher Scientific, Inc., Waltham, MA, USA) and antibiotics, $100 \mathrm{IU} / \mathrm{ml}$ penicillin and $100 \mathrm{mg} / \mathrm{ml}$ streptomycin, in $5 \% \mathrm{CO}_{2}$ at $37^{\circ} \mathrm{C}$. The MCF7 cells were infected with the lentiviruses Lenti-AEG1 or negative control, Lenti-control, at a multiplicity of infection of 10 . The sequence of the short hairpin (sh)RNA targeting AEG1 contained within the lentiviral vector was 5'-AACTTACAACCGCATCATT-3'. The MCF7 cells were divided into the following two experimental groups: Lenti-AEG1 group, consisting of Lenti-AEG1-infected cells; lenti-control group, consisting of Lenti-control-infected cells.

$R N A$ isolation and reverse transcription-quantitative polymerase chain reaction (RT- $q P C R)$. Total RNA was extracted from the cells using the E.Z.N.A. Total RNA kit I (Omega Bio-Tek, Inc., Norcross, GA, USA) according to the protocol of the manufacturer. The mRNA was subsequently reversely transcribed to cDNA using the PrimeScript RT reagent kit with gDNA Eraser (Takara Bio, Inc., Otsu, Japan), according to the manufacturer's instructions. RT-qPCR was carried out using SYBR Premix Ex Taq II (Takara Bio, Inc.) on a Stratagene MX3000P Real Time PCR machine (Agilent Technologies, Inc., Santa Clara, CA, USA). The thermocycling conditions were as follows: $95^{\circ} \mathrm{C}$ for $30 \mathrm{sec}$; followed by 39 cycles of $95^{\circ} \mathrm{C}$ for $5 \mathrm{sec}$ and $69^{\circ} \mathrm{C}$ for $34 \mathrm{sec}$. GADPH was used as the reference gene. The experiment was repeated three times, and data were normalized using the $2^{-\Delta \Delta \mathrm{Cq}}$ method (24). The following primers were used: AEG1 forward, 5'-AAA TAGCCAGCCTATCAAGACTC-3' and reverse, 5'-TTCAGA CTTGGTCTGTGAAGGAG-3'; adenomatous polyposis coli protein (APC) forward, 5'-ACCCAGCCGACCTAGCCC AT-3' and reverse, 5'-ACCATTGGCTCCCCGTGACCT-3'; axin forward, 5'-CTCCAGTAGACGGTACAGCGAAG-3' and reverse, 5'-GCATAGCCGGCATTGACATA-3'; and GAPDH forward, 5'-CGCTCTCTGCTCCTCCTGTT-3' and reverse 5'-CCATGGTGTCTGAGCGATGT-3'.

Cell proliferation assay. A cell proliferation assay was performed using a Cell Counting kit-8 (CCK-8) assay (Dojindo Molecular Technologies, Inc., Kumamoto, Japan), according to the protocol of the manufacturer.

Colony-formation assay. Each MCF7 cell group was seeded in 6-well plates in triplicate at a density of 2,000 cells/well and incubated for 10 days at $37^{\circ} \mathrm{C}$. The culture medium was replaced every two days. Colonies of $>50$ cells were counted using an inverted microscope (Olympus-IX51; Olympus Corporation, Tokyo, Japan) subsequent to 10 days of culture. The rate of colony formation was calculated using the following equation: Colony formation rate $(\%)=($ total number of colonies / number of seeded cells) x100\%.

Transwell invasion assay. Transwell chambers (24-well) coated with Matrigel (BD Biosciences, Franklin Lakes, NJ, USA) were used for cell invasion assays. The MCF7 cells $\left(1 \times 10^{5}\right.$ cells/well) were seeded in the upper chambers of the
Transwell plate. A total of $800 \mu 1$ DMEM supplemented with $20 \%$ FBS was added to the lower chamber and served as the chemoattractant. Subsequent to a 24-h incubation, washed with PBS to remove the non-migratory cells, and the cells on the lower surface of the membrane were fixed with $10 \%$ formaldehyde solution and then stained with crystal violet staining solution. The cells in $\geq 5$ randomly selected microscopic fields (Olympus-BX51; Olympus Corporation; magnification, x200) were counted and images were captured.

Western blotting. Western blotting was performed as described previously (11). The primary antibodies used in this study were as follows: Rabbit anti-AEG1 (dilution, 1:20,000; cat. no. ab124789; Abcam, Cambridge, UK), rabbit anti-MMP9 (dilution, 1:500; cat. no. BS6893; Bioworld Technology, Inc., St. Louis Park, MN, USA), rabbit anti-cyclinD1 (dilution, 1:1,000; cat. no. 2978S; Cell Signaling Technology, Inc., Danvers, MA, USA), rabbit anti-c-Myc (dilution, 1:500; cat. no. BS1244; Bioworld Technology, Inc.), rabbit anti-axin (dilution, 1:1,000; cat. no. 2087S; Cell Signaling Technology, Inc.), rabbit anti-APC (dilution, 1:1,000; cat. no. BS1017; Bioworld Technology, Inc.), mouse anti- $\beta$-catenin (dilution, 1:500; cat. no. SC-7963; Santa Cruz Biotechnology, Inc.), rabbit anti-GSK3 $\beta$ (dilution, 1:1,000; cat. no. AG751; Beyotime Institute of Biotechnology, Haimen, China), rabbit anti-p-GSK3 $\beta$ (dilution, 1:1,000; cat. no. AG753; Beyotime Institute of Biotechnology). The secondary antibody used in the present study was a goat anti-rabbit IgG-horseradish peroxidase (dilution, 1:5,000; cat. no. 7074P2; Cell Signaling Technology, Inc) or a goat anti-mouse IgG-horseradish peroxidase (dilution, 1:4,000; Cell Signaling Technology, Inc.; cat. no. 14709S).

Statistical analysis. All experiments were repeated $\geq 3$ independent times. All the data are expressed as the mean \pm standard deviation and were analyzed using SPSS 13.0 (SPSS, Inc., Chicago, IL, USA). Differences between individual groups were analyzed by Student's $t$-tests. $\mathrm{P}<0.05$ was considered to indicate a statistically significant difference.

\section{Results}

AEG1 expression is upregulated in breast cancer cell lines. To investigate the role of AEG1 in human breast cancer cells, the present study examined the expression of AEG1 in breast cancer cells, including the estrogen receptor (ER) $\alpha$-negative cell line MDA-MB-231, the ER $\alpha$-positive MCF7 cell line, the human epidermal growth factor receptor 2 (HER2)-positive SK-BR-3 cell line and the normal mammary epithelial MCF10A cell line, using RT-qPCR and western blot analysis (Fig. 1A and B). The data demonstrated that the expression level of AEG1 expression is higher in all breast cancer cells compared with normal MCF10A cells (MCF7 mRNA expression, $\mathrm{P}=0.0004$; MDA-MB-231 mRNA expression, $\mathrm{P}=0.0439$; SK-BR-3 mRNA expression, $\mathrm{P}=0.02$; MCF7 protein expression, $\mathrm{P}=0.035$; MDA-MB-231 protein expression, $\mathrm{P}=0.0089$; SK-BR-3 protein expression, $\mathrm{P}=0.0397$ ), and the mRNA expression level was $\sim 3.7$ times higher in MCF7 cells compared with MCF10A cells. 
Specific downregulation of AEG-1 expression by the lentiviral vector expressing shRNA. To determine whether AEG1 served a role in the proliferation and invasion of breast cancer, the present study infected MCF-7 cells with the lentivirus Lenti-AEG1 and measured the level of AEG1 expressed. The efficiency of infection in the MCF7 cell line was $>95 \%$ at $72 \mathrm{~h}$ post-infection, as indicated by the expression of green fluorescent protein (Fig. 2A). To determine the efficiency of AEG1 expression, RT-qPCR and western blot analysis were performed. RT-qPCR analysis demonstrated that the level of AEG1 mRNA expression in the Lenti-AEG1 group was significantly lower than the level in the Lenti-control group $(\mathrm{P}=0.0033$; Fig. 2B). Western blot analysis also revealed a corresponding decrease in the protein levels $(\mathrm{P}=0.011$; Fig. $2 \mathrm{C})$. These results indicate that Lenti-AEG1 effectively decreased the mRNA and protein expression of AEG1 in MCF7 human breast cancer cells.

AEG1 regulates breast cancer cell proliferation and invasion in vitro. To investigate the effect of AEG1 on breast cancer progression and aggressiveness, the present study performed cell proliferation, colony formation and Transwell assays. As demonstrated in Fig. 3A, silencing AEG1 in the MCF7 cells significantly reduced the number of colonies in Lenti-AEG1 group cells compared with the control cells $(\mathrm{P}=0.0423)$. Silencing AEG1 expression in the MCF7 cells, which exhibited a low-level expression of AEG1, significantly reduced the cell growth rate compared with the cells of control group ( $\mathrm{P}=0.012$, Fig. 3B). In addition, the invasive capability of the MCF7 cells was reduced by $>75 \%$ when AEG1 expression was reduced by Lenti-AEG1 virus, compared with the control cells ( $\mathrm{P}=0.041$, Fig. $3 \mathrm{C})$. The relative levels of cyclin $\mathrm{D} 1(\mathrm{P}=0.036)$, MMP9 $(\mathrm{P}=0.023)$ and $\mathrm{c}-\mathrm{Myc}(\mathrm{P}=0.01)$ were significantly lower in Lenti-AEG1group cells compared with the Lenti-control group cells. The results indicate that AEG1 knockdown inhibits cell proliferation, and is involved in the metastatic process of breast cancer.

AEG1 silencing inhibits the Wnt/ $\beta$-catenin signaling in breast cancer MCF7 cells. A range of signaling pathways, including the Wnt/\$-catenin pathway, regulates breast cancer cell proliferation and invasion. Therefore, the present study investigated the effect of AEG1 silencing on Wnt/ $\beta$-catenin activation in MCF7 cells using western blotting. The relative mRNA levels of axin and APC in the Lenti-AEG1 cell group were significantly higher than the levels of the Lenti-control group cells $(\mathrm{P}=0.0085$ and $\mathrm{P}=0.0047$, respectively; Fig. 4A). A similar pattern of the relative APC and axin protein levels of the aforementioned genes was detected in the Lenti-control and Lenti-AEG1 group cells ( $\mathrm{P}=0.0026$ and $\mathrm{P}=0.022$, respectively; Fig. 4B). The knockdown of AEG-1 also resulted in a decreased level of glycogen synthase kinase $3 \beta$ (GSK3 $\beta$ ) phosphorylation ( $\mathrm{P}=0.029$; Fig. $4 \mathrm{C})$. The relative levels of nuclear and cytoplasmic $\beta$-catenin were detected by western blotting, and the ratio of nuclear to cytoplasmic $\beta$-catenin was significantly lower in the Lenti-control group cells, as compared with in the Lenti-AEG1 group cells $(\mathrm{P}=0.016$ and $\mathrm{P}=0.047$, respectively; Fig. 4D). These results suggest that AEG1 silencing inhibits Wnt/ $\beta$-catenin activation, which is crucial for the proliferation and invasion of breast cancer cells.
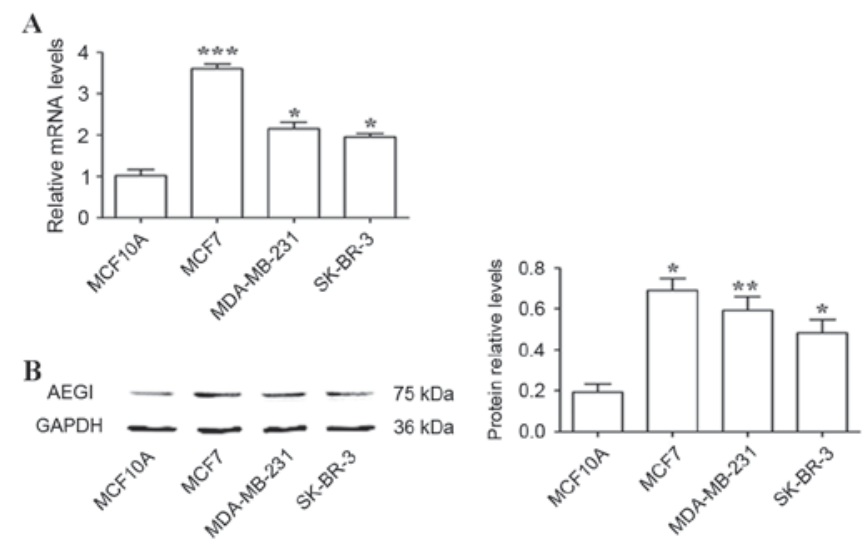

Figure 1. Expression of AEG1 in breast cancer cells was examined using reverse transcription-quantitative polymerase reaction and western blot analysis. (A) Relative AEG1 mRNA expression levels in numerous cell lines. (B) Relative AEG1 protein expression levels in various cell lines. ${ }^{*} \mathrm{P}<0.05$, ${ }^{* *} \mathrm{P}<0.01,{ }^{* * *} \mathrm{P}<0.001$, compared with MCF10A cells. AEG1, astrocyte elevated gene-1.

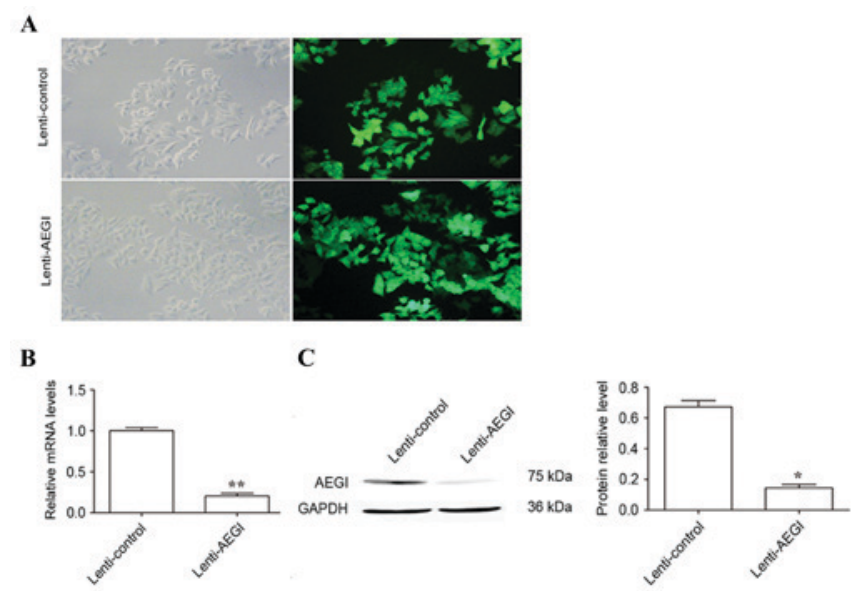

Figure 2. AEG1 expression was decreased in in breast cancer MCF7 cells following lentiviral infection. (A) The morphology of MCF7 cells was evaluated using a light microscope, $72 \mathrm{~h}$ subsequent to infection with Lenti-AEG1; magnification, $x 200$. (B) Quantitative polymerase chain reaction revealed the relative AEG1 mRNA levels normalized to GAPDH. (C) Western blot analysis depicting protein levels of AEG1. GAPDH was used as an internal control for equal loading. ${ }^{*} \mathrm{P}<0.05,{ }^{* *} \mathrm{P}<0.01$. AEG1, astrocyte elevated gene-1; lenti, lentivirus.

\section{Discussion}

Previous studies have identified that AEG-1 serves a crucial role in tumor progression, including transformation, evasion of apoptosis, invasion, metastasis and chemoresistance $(25,26)$. AEG1 has been reported to be associated with the activation of several signaling pathways including phosphoinositide 3-kinase (PI3K)/protein kinase B (AKT) and nuclear factor (NF)кB (27-29). Zhu et al (30) demonstrated that AEG1 regulates the expression of vascular endothelial growth factor via the PI3K/AKT signaling pathway, which may facilitate the metastasis of squamous cell carcinoma of the head and neck. AEG1 overexpression mediates trastuzumab resistance by phosphatase and tensin homolog inhibition through an NFkB-dependent pathway in HER2-positive breast cancer (29). 


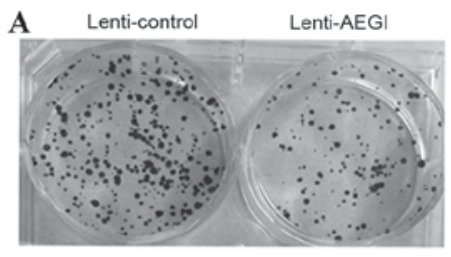

B
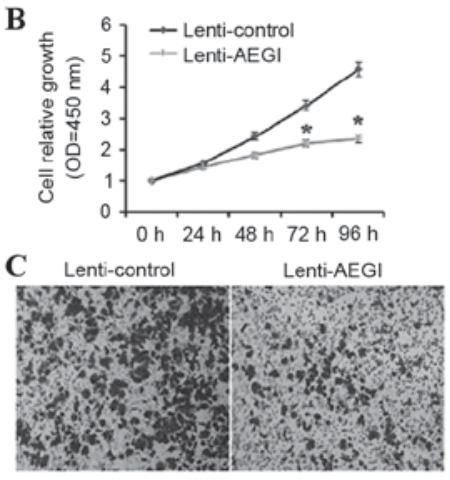

D

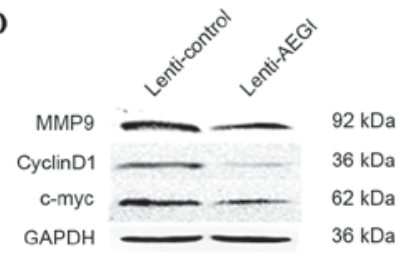

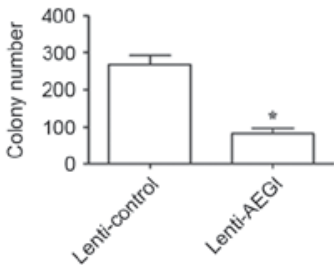
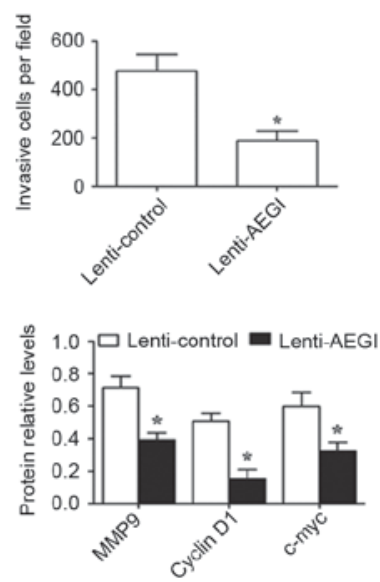

Figure 3. AEG1 regulates breast cancer cell proliferation and invasion (A) Clone formation assay. A marked difference in survival was observed between the Lenti-control group cells and the Lenti-AEG1 group cells. (B) Proliferation of AEG1 silenced cells was determined using a Cell Counting kit- 8 assay, at the indicated number of days. (C) Images are representative fields of cell invasion on the Transwell chamber (magnification, x200); bar graphs represent the relative fold difference of invasive cell numbers, compared with the control cells. (D) Relative cyclin D1, MMP9, and c-Myc protein levels were detected by western blotting. ${ }^{*} \mathrm{P}<0.05$. AEG1, astrocyte elevated gene-1; Lenti, lentivirus; MMP, matrix metalloproteinase.

The present study demonstrated that AEG1 is overexpressed in breast cancer cells, compared with normal mammary epithelial cells. Notably, the present study also identified a novel aspect of the molecular mechanism by which AEG1 augments breast cancer progression.

The current study explored the function of AEG1 in the proliferation and invasion of MCF7 breast cancer cells. The results demonstrated that the knockdown of AEG1, mediated by lentiviruses, inhibited the proliferation and invasion in MCF7 cells in vitro. Notably, the present study also identified that AEG1 silencing inhibits the expression of cyclin D1, c-Myc and MMP9. Previous studies suggested that cyclin D1and c-Myc are associated with cell proliferation, and are involved in tumorigenesis and deterioration (31-33). Cyclin D1 is a key protein that serves an essential role on the biologic effects of breast cancer cells, and the overexpression of the protein has been demonstrated to be associated with tumor stage, lymph node metastasis and a poor prognosis in breast cancer $(34,35)$. The oncoprotein c-Myc is frequently overexpressed in breast cancer, and considered to serve an important role in carcinogenesis and tumor progression (36). Bidwell et al (37) demonstrated that targeted c-Myc inhibitory polypeptides
A

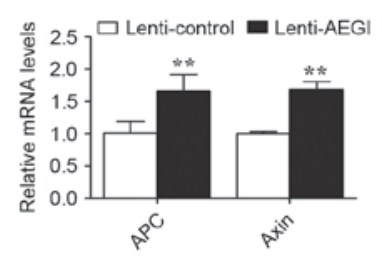

B
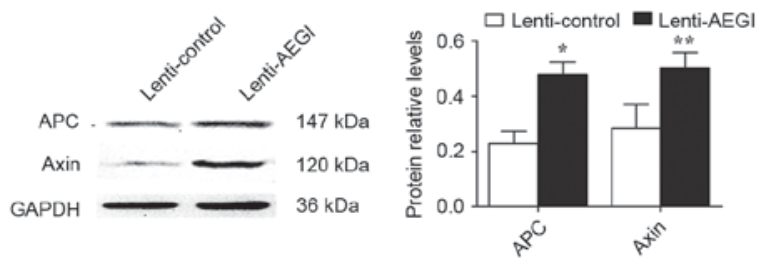

C
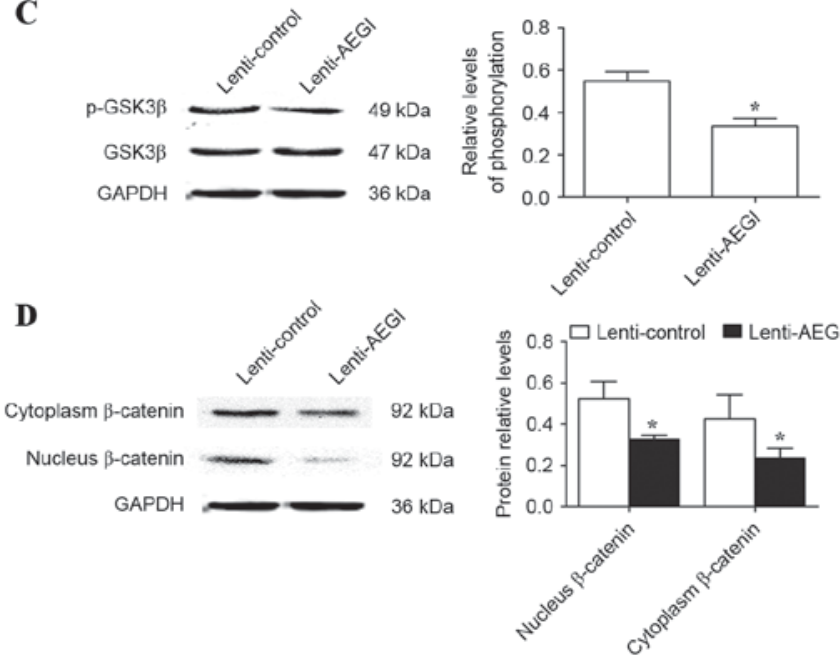

Figure 4. AEG1 silencing inhibits Wnt/ $\beta$-catenin signaling in MCF7 breast cancer cells. (A and B) Quantitative polymerase chain reaction and western blotting in various cell groups detected the relative mRNA and protein levels of axin and APC. (C) The levels of GSK $3 \beta$ expression and GSK $3 \beta$ phosphorylation were detected by western blotting. (D) Relative nuclear and cytoplasmic $\beta$-catenin protein levels were detected by western blotting. ${ }^{*} \mathrm{P}<0.05,{ }^{* *} \mathrm{P}<0.01$. AEG1, astrocyte elevated gene-1; APC, adenomatous polyposis coli protein; GSK3 $\beta$, glycogen synthase kinase 3; p, phosphorylated; Lenti, lentivirus.

significantly suppressed breast cancer tumor growth in an orthotopic mouse model of breast cancer. Liu et al (38) identified that klf3a, a subunit of the kinesin-II motor protein, promotes cell proliferation and invasion via Wnt signaling in advanced prostate cancer, modulating cyclin D1 and c-Myc expression. It has been reported that the excessive production of MMP9, the major MMP, is associated with the metastasis of breast cancer. The suppression of MMP9 expression significantly inhibits tumor cell migration in tamoxifen-resistant breast cancer cells (39). Those data support the hypothesis that the canonical $\mathrm{Wnt} / \beta$-catenin signaling pathway is involved in the aforementioned processes.

Evidently, the Wnt/ $\beta$-catenin signaling pathway serves a crucial role in cell proliferation and tumor cell invasion (40-42). The effect on the expression of the Wnt/ $\beta$-catenin signaling pathway was investigated in the present study by western blotting in order to elucidate the underlying mechanisms. The results of the western blotting demonstrated that the knockdown of AEG1 expression significantly increased the protein expression levels of APC and axin, whilst also decreasing the level of GSK3 $\beta$ phosphorylation and reducing 
the ratio of cytoplasmic to nuclear $\beta$-catenin in MCF7 breast cancer cells. The results indicate that AEG1 silencing inhibits Wnt/ $\beta$-catenin activation in MCF7 breast cancer cells, leading to poor cell proliferation and invasiveness.

In summary, the present study demonstrated that AEG1 is a novel agonist of the Wnt signaling pathway in human breast cancer, and that it is associated with breast cancer progression and metastasis. AEG1 regulates breast cancer cell proliferation and invasion, at least in part, through the induction of $\beta$-catenin phosphorylation, inhibiting the nuclear translocation of $\beta$-catenin, and regulation of transcriptional activation of three Wnt target genes: Cyclin D1, c-Myc and MMP9. Furthermore, the results indicate that AEG1 may be a potential therapeutic target for types of breast cancer in which $\mathrm{Wnt} / \beta$-catenin signaling is activated.

\section{References}

1. Amaro J, Severo M, Vilela S, Fonseca S, Fontes F, La Vecchia C and Lunet N: Patterns of breast cancer mortality trends in Europe. Breast 22: 244-253, 2013.

2. Justo N, Wilking N, Jönsson B, Luciani S and Cazap E: A review of breast cancer care and outcomes in Latin America. Oncologist 18: 248-256, 2013.

3. Li N, Zheng RS, Zhang SW, Zou XN, Zeng HM, Dai Z and Chen WQ: Analysis and prediction of breast cancer incidence trend in China. Zhonghua Yu Fang Yi Xue Za Zhi 46: 703-707, 2012 (In Chinese).

4. Dodiyi-Manuel A and Wakama IE: Predispositions of carcinoma of the breast: A review. Niger J Med 23: 7-12, 2014.

5. Nasr Z, Robert F, Porco JA Jr, Muller WJ and Pelletier J: eIF4F suppression in breast cancer affects maintenance and progression. Oncogene 32: 861-871, 2013.

6. Xu JW, Li QQ, Tao LL, Cheng YY, Yu J, Chen Q, Liu XP and $\mathrm{Xu}$ ZD: Involvement of EGFR in the promotion of malignant properties in multidrug resistant breast cancer cells. Int J Oncol 39: 1501-1509, 2011.

7. Huang O, Zhang W, Zhi Q, Xue X, Liu H, Shen D, Geng M, Xie Z and Jiang M: Teriflunomide, an immunomodulatory drug, exerts anticancer activity in triple negative breast cancer cells. Exp Biol Med (Maywood) 240: 426-437, 2015.

8. Shargh SA, Sakizli M, Khalaj V, Movafagh A, Yazdi H, Hagigatjou E, Sayad A, Mansouri N, Mortazavi-Tabatabaei SA and Khorram Khorshid HR: Downregulation of E-cadherin expression in breast cancer by promoter hypermethylation and its relation with progression and prognosis of tumor. Med Oncol 31: 250, 2014.

9. Wan L and Kang Y: Pleiotropic roles of AEG-1/MTDH/LYRIC in breast cancer. Adv Cancer Res 120: 113-134, 2013.

10. Emdad L, Das SK, Dasgupta S, Hu B, Sarkar D and Fisher PB: AEG-1/MTDH/LYRIC: Signaling pathways, downstream genes, interacting proteins, and regulation of tumor angiogenesis. Adv Cancer Res 120: 75-111, 2013.

11. Xu C, Kong X, Wang H, Zhang N, Kong X, Ding X, Li X and Yang Q: MTDH mediates estrogen-independent growth and tamoxifen resistance by down-regulating PTEN in MCF-7 breast cancer cells. Cell Physiol Biochem 33: 1557-1567, 2014.

12. Nohata N, Hanazawa T, Kikkawa N, Mutallip M, Sakurai D, Fujimura L, Kawakami K, Chiyomaru T, Yoshino H, Enokida $\mathrm{H}$, et al: Tumor suppressive microRNA-375 regulates oncogene AEG-1/MTDH in head and neck squamous cell carcinoma (HNSCC). J Hum Genet 56: 595-601, 2011.

13. Milhem MM, Knutson T, Yang S, Zhu D, Wang X, Leslie KK and Meng X: Correlation of MTDH/AEG-1 and HOTAIR expression with metastasis and response to treatment in sarcoma patients. J Cancer Sci Ther S5: 004, 2011.

14. Guo F, Wan L, Zheng A, Stanevich V, Wei Y, Satyshur KA, Shen M, Lee W, Kang Y and Xing Y: Structural insights into the tumor-promoting function of the MTDH-SND1 complex. Cell Rep 8: 1704-1713, 2014

15. Deng N and Feng Y: Expression of EphA7 and MTDH and clinicopathological significance in the squamous cell cancer of the tongue. Zhong Nan Da Xue Xue Bao Yi Xue Ban 36: 1195-1198, 2011 (In Chinese)
16. Kypta RM and Waxman J: Wnt/ $/$-catenin signalling in prostate cancer. Nat Rev Urol 9: 418-428, 2012.

17. Meng X, Zhu D, Yang S, Wang X, Xiong Z, Zhang Y, Brachova P and Leslie KK: Cytoplasmic metadherin (MTDH) provides survival advantage under conditions of stress by acting as RNA-binding protein. J Biol Chem 287: 4485-4491, 2012.

18. Clevers $\mathrm{H}$ and Nusse R: Wnt/ $\beta$-catenin signaling and disease. Cell 149: 1192-1205, 2012.

19. VON Schulz-Hausmann SA, Schmeel LC, Schmeel FC and Schmidt-Wolf IG: Targeting the Wnt/beta-catenin pathway in renal cell carcinoma. Anticancer Res 34: 4101-4108, 2014.

20. Piven' OO, Pal'chevs'ka OL and Lukash LL: The Wnt/beta-catenin signaling in embryonic cardiogenesis, postnatal development and myocardium reconstruction. Tsitol Genet 48: 72-183, 2014 (In Ukrainian).

21. Thompson MD and Monga SP: Wnt/beta-catenin signaling in liver health and disease. Hepatology 45: 1298-1305, 2007.

22. Zhang DP, Li XW and Lang JH: Prognostic Value of $\beta$-catenin expression in breast cancer patients: A meta-analysis. Asian Pac J Cancer Prev 16: 5625-5633, 2015.

23. Chen Z, He X, Jia M, Liu Y, Qu D, Wu D, Wu P, Ni C, Zhang Z, Ye J, et al: $\beta$-catenin overexpression in the nucleus predicts progress disease and unfavourable survival in colorectal cancer: A meta-analysis. PLoS One 8: e63854, 2013.

24. Livak KJ and Schmittgen TD: Analysis of relative gene expression data using real-time quantitative PCR and the 2(-Delta Delta C(T)) method. Methods 25: 402-408, 2001.

25. Meng X, Thiel KW and Leslie KK: Drug resistance mediated by AEG-1/MTDH/LYRIC. Adv Cancer Res 120: 135-157, 2013.

26. Hu G, Wei Y and Kang Y: The multifaceted role of MTDH/AEG-1 in cancer progression. Clin Cancer Res 15: 5615-5620, 2009.

27. Lee SG, Kang DC, DeSalle R, Sarkar D and Fisher PB: AEG-1/MTDH/LYRIC, the beginning: Initial cloning, structure, expression profile, and regulation of expression. Adv Cancer Res 120: 1-38, 2013.

28. Hu G, Wei Y and Kang Y: The multifaceted role of MTDH/AEG-1 in cancer progression. Clin Cancer Res 15: 5615-5620, 2009.

29. Du C, Yi X, Liu W, Han T, Liu Z, Ding Z, Zheng Z, Piao Y, Yuan J, Han Y, et al: MTDH mediates trastuzumab resistance in HER2 positive breast cancer by decreasing PTEN expression through an $\mathrm{NF \kappa B}$-dependent pathway. BMC Cancer 14:869, 2014.

30. Zhu GC, Yu CY, She L, Tan HL, Li G, Ren SL, Su ZW, Wei M, Huang DH, Tian YQ, et al: Metadherin regulation of vascular endothelial growth factor expression is dependent upon the PI3K/Akt pathway in squamous cell carcinoma of the head and neck. Medicine (Baltimore) 94: e502, 2015.

31. Casimiro MC, Di Sante G, Crosariol M, Loro E, Dampier W, Ertel A, Yu Z, Saria EA, Papanikolaou A, Li Z, et al: Kinase-independent role of cyclin D1 in chromosomal instability and mammary tumorigenesis. Oncotarget 6: 8525-8538, 2015.

32. Richart L, Carrillo-de Santa Pau E, Río-Machín A, de Andrés MP, Cigudosa JC, Lobo VJ and Real FX: BPTF is required for c-MYC transcriptional activity and in vivo tumorigenesis. Nat Commun 7: 10153, 2016.

33. Liao DJ, Thakur A, Wu J, Biliran H and Sarkar FH: Perspectives on c-Myc, Cyclin D1, and their interaction in cancer formation, progression, and response to chemotherapy. Crit Rev Oncog 13: 93-158, 2007.

34. El-Hafez AA, El Aaty Shawky A and Hasan B: Cyclin D1 overexpression associates with favourable prognostic factors in invasive breast carcinoma. Cancer Biomark 12: 149-154, 2012.

35. Wang X and Zou S: The relationship of CyclinD1 and estrogen receptor expression in the process of proliferation and metastasis in breast neoplasm. J Tongji Med Univ 21: 231-232, 2001.

36. McNeil CM, Sergio CM, Anderson LR, Inman CK, Eggleton SA, Murphy NC, Millar EK, Crea P, Kench JG, Alles MC, et al: c-Myc overexpression and endocrine resistance in breast cancer. J Steroid Biochem Mol Biol 102: 147-155, 2006.

37. Bidwell GL III, Perkins E and Raucher D: A thermally targeted c-Myc inhibitory polypeptide inhibits breast tumor growth. Cancer Lett 319: 136-143, 2012.

38. Liu Z, Rebowe RE, Wang Z, Li Y, Wang Z, DePaolo JS, Guo J, Qian C and Liu W: KIF3a promotes proliferation and invasion via Wnt signaling in advanced prostate cancer. Mol Cancer Res 12: 491-503, 2014.

39. Jang SY, Kim A, Kim JK, Kim C, Cho YH, Kim JH and Lee JY: Metformin inhibits tumor cell migration via down-regulation of MMP9 in tamoxifen-resistant breast cancer cells. Anticancer Res 34: 4127-4134, 2014. 
40. Yuan JB, Yang LY, Tang ZY, Zu XB and Qi L: Down-regulation of EZH2 by RNA interference inhibits proliferation and invasion of ACHN cells via the Wnt/ $\beta$ - catenin pathway. Asian Pac J Cancer Prev 13: 6197-6201, 2012.

41. Guo Q, Wu M, Lian P, Liao M, Xiao Z, Wang X and Shen S: Synergistic effect of indomethacin and NGX6 on proliferation andinvasion by human colorectal cancer cells through modulation of theWnt/beta-catenin signaling pathway. Mol Cell Biochem 330: 71-81, 2009.
42. Zhao Z, Lu P, Zhang H, Xu H, Gao N, Li M and Liu C: Nestin positively regulates the $\mathrm{Wnt} / \beta$-catenin pathway and theproliferation, survival and invasiveness of breast cancer stem cells. Breast Cancer Res 16: 408, 2014. 